\title{
Lack of NMDA Receptor Subtype Selectivity for Hippocampal Long-Term Potentiation
}

\author{
Sven Berberich, ${ }^{1 *}$ Pradeep Punnakkal, ${ }^{1 *}$ Vidar Jensen, ${ }^{2}$ Verena Pawlak, ${ }^{1}$ Peter H. Seeburg, ${ }^{1}$ Øivind Hvalby, ${ }^{2}$ and \\ Georg Köhr ${ }^{1}$ \\ ${ }^{1}$ Department of Molecular Neurobiology, Max-Planck-Institute for Medical Research, D-69120 Heidelberg, Germany, and ${ }^{2}$ Molecular Neurobiology \\ Research Group, Institute of Basic Medical Sciences, University of Oslo, N-0317 Oslo, Norway
}

\begin{abstract}
NMDA receptor (NMDAR) 2A (NR2A)- and NR2B-type NMDARs coexist in synapses of CA1 pyramidal cells. Recent studies using pharmacological blockade of NMDAR subtypes proposed that the NR2A type is responsible for inducing long-term potentiation (LTP), whereas the NR2B type induces long-term depression (LTD). This contrasts with the finding in genetically modified mice that NR2B-type NMDARs induce LTP when NR2A signaling is absent or impaired, although compensatory mechanisms might have contributed to this result. We therefore assessed the contribution of the two NMDAR subtypes to LTP in mouse hippocampal slices by different induction protocols and in the presence of NMDAR antagonists, including the NR2A-type blocker NVP-AAM077, for which an optimal concentration for subtype selectivity was determined on recombinant and native NMDARs. Partial blockade of NMDA EPSCs by 40\%, either by preferentially antagonizing NR2A- or NR2B-type NMDARs or by the nonselective antagonist D-AP-5, did not impair LTP, demonstrating that hippocampal LTP induction can be generated by either NMDAR subtype.
\end{abstract}

Key words: NVP-AAM077; PEAQX; CP-101,606; recombinant; gene-targeted mouse; partial blockade; pairing

\section{Introduction}

During postnatal development, the hippocampal signaling cascades for long-term potentiation (LTP) induction switch (Yasuda et al., 2003) and the NMDA receptor (NMDAR) 2B (NR2B)/NMDAR 2A (NR2A) ratio decreases (Sans et al., 2000). At postnatal day 28 (P28), rodents express comparable amounts of these NR2 subunits (Sans et al., 2000), but the specific signaling roles of the NMDAR subtypes are still unclear. Recent studies using NMDAR subtype blockade proposed that NR2A-type NMDARs induce LTP and NR2B-type NMDARs induce longterm depression (LTD) (Liu et al., 2004; Massey et al., 2004). In contrast, a role of NR2B-type NMDARs in LTP has been demonstrated in genetically modified mice, with overexpression of NR2B or upregulated NR2B expression leading to enhanced LTP (Tang et al., 1999; Wong et al., 2002) and activation of NR2B-type NMDARs restoring LTP in mice with absent or impaired NR2A signaling (Kiyama et al., 1998; Köhr et al., 2003). Because compensatory mechanisms might have contributed to the results from genetically modified mice, we have now used NR2-specific antagonists to test the contribution of NMDAR subtypes to hippocampal LTP.

Received May 12, 2005; revised June 15, 2005; accepted June 16, 2005.

We thank Dr. M. Mishina (University Tokyo) for providing GluRe1 (NR2A) KO mice, Dr. Y. P. Auberson (Novartis Pharma AG, Basel, Switzerland) for discussion and the gift of NVP-AAM077, and Pfizer (Groton, CT) for the gift of (P-101,606. We also thank Dr. F. N. Single, J. Kling, and Liya Pan for experimental help.

*S.B. and P.P contributed equally to this work.

Correspondence should be addressed to Dr. Georg Köhr, Department of Molecular Neurobiology, Max-Planck-Institute for Medical Research, Jahnstrasse 29, D-69120 Heidelberg, Germany. E-mail: kohr@mpimf-heidelberg.mpg.de. DOI:10.1523/JNEUROSCI.1905-05.2005

Copyright $\odot 2005$ Society for Neuroscience $\quad 0270-6474 / 05 / 256907-04 \$ 15.00 / 0$

\section{Materials and Methods}

Recombinant receptors. Human embryonic kidney 293 (HEK293) cells were cotransfected with plasmids encoding NR1-1a, NR2A, or NR2B and green fluorescent protein (GFP) (Chen and Okayama, 1987). Forty-eight hours after transfection, cells were continuously perfused with the following (in mM): $135 \mathrm{NaCl}, 5.4 \mathrm{KCl}, 1.8 \mathrm{CaCl}_{2}$, and 5 HEPES, pH 7.3. Patch electrodes (4-7 M $\Omega$ ) were filled with the following (in $\mathrm{mM}$ ): 140 CsCl, 2 MgATP, 10 EGTA, and 10 HEPES, pH 7.3, 290-305 mOsm. GFP-labeled cells were lifted from the coverslip, and whole-cell currents were activated at $-60 \mathrm{mV}$ in the presence of $50 \mu \mathrm{M}$ glycine by fast applying $1 \mathrm{~mm}$ glutamate from a Piezo-driven double-barreled pipette using an EPC-9 amplifier (HEKA Elektronik, Lambrecht, Germany), either in the absence or the presence of NR2 antagonists [e.g., the NR2A-specific antagonist NVP-AAM077 (NVP) (Novartis Pharma, Basel, Switzerland) or the NR2B-specific antagonist CP-101,606 (CP) (Pfizer, Groton, CT)]. NVP-AAM077 [ $\left(1 R, 1^{\prime} S\right)$-PEAQX], the full name of which is $[(R)-[(S)$ 1-(4-bromo-phenyl)-ethylamino]-(2,3-dioxo-1,2,3,4-tetrahydroquinoxalin-5-yl)-methyl]-phosphonic acid, has first been reported as (1RS, $1^{\prime} S$ )-diastereoisomeric mixture in the study by Auberson et al. (2002). More recent studies (Feng et al., 2004; Liu et al., 2004), including ours, used NVP-AAM077. Some reports (Feng et al., 2004) refer to NVPAAM077 as PEAQX.

Whole-cell experiments. All experimental procedures were in accordance with the animal welfare guidelines of the Max-Planck-Society. The brain was removed from deeply anesthetized P28 mice (halothane), and transverse hippocampal slices $(250 \mu \mathrm{m})$ were prepared and incubated for $30 \mathrm{~min}$ at $35^{\circ} \mathrm{C}$ in artificial CSF (ACSF) containing the following (in mM): $125 \mathrm{NaCl}, 25 \mathrm{NaHCO}_{3}, 2.5 \mathrm{KCl}, 1.25 \mathrm{NaH}_{2} \mathrm{PO}_{4}, 1 \mathrm{MgCl}_{2}, 25$ D-glucose, and $2 \mathrm{CaCl}_{2}$, bubbled with $95 \% \mathrm{O}_{2} / 5 \% \mathrm{CO}_{2}, \mathrm{pH}$ 7.4. Patch pipettes were pulled from borosilicate glass capillaries and had resistances of 4-6 $\mathrm{M} \Omega$ when filled with the following (in $\mathrm{mm}$ ): $125 \mathrm{Cs}$-gluconate, $20 \mathrm{CsCl}, 10$ $\mathrm{NaCl}, 10$ HEPES, 0.2 EGTA, 4 MgATP, and 0.3 $\mathrm{Na}_{3} \mathrm{GTP}, \mathrm{pH} 7.3,290-$ $305 \mathrm{mOsm}$. Liquid junction potentials were not corrected. Series resis- 
tances (15-30 M $\Omega$ ) and input resistances (100$300 \mathrm{M} \Omega$ ) were continuously monitored by measuring the peak and steady-state currents in response to hyperpolarizing pulses $(-5 \mathrm{mV} ; 20$ $\mathrm{ms}$ ). All patch experiments were performed at room temperature.

EPSCs were activated by stimulating the Schaffer collaterals $\sim 150 \mu \mathrm{m}$ distant from the CA1 cell body with a glass electrode filled with $1 \mathrm{M} \mathrm{NaCl}$. NMDA EPSCs were recorded at -40 and +40 $\mathrm{mV}$ in ACSF (see above) containing $10 \mu \mathrm{M}$ bicuculline methiodide (BMI), $5 \mu \mathrm{M}$ 2,3-dihydroxy-6nitro-7-sulfonyl-benzo[f] quino-xaline-7-sulfonamide (NBQX), and $10 \mu \mathrm{m}$ glycine. For LTP recordings, patch pipettes were filled with the following (in mM): 120 Cs-gluconate, $10 \mathrm{CsCl}, 10$ HEPES, $8 \mathrm{NaCl}, 0.2$ EGTA, 2 MgATP, 0.3 $\mathrm{Na}_{3} \mathrm{GTP}$, and 10 phosphocreatine. Composite EPSCs were evoked in solutions containing the following (in mM): $124 \mathrm{NaCl}, 26 \mathrm{NaHCO}_{3}, 1.25$ $\mathrm{NaH}_{2} \mathrm{PO}_{4}, 2.5 \mathrm{KCl}, 4 \mathrm{CaCl}_{2}, 4 \mathrm{MgSO}_{4}, 10 \mathrm{D}-$ glucose, 0.010 glycine, and 0.010 BMI, pH 7.3, 290-305 mOsm. In some experiments, D-2amino-5-phosphonopentanoic acid (D-AP-5; Tocris Cookson, Bristol, UK), NVP-AAM077, or CP-101,606 was present. LTP was induced by pairing low-frequency stimulation (LFS) (120 pulses; $0.7 \mathrm{~Hz}$ ) in the test (stratum radiatum) but not in the control pathway (stratum oriens) with postsynaptic depolarization to $0 \mathrm{mV}$ for $3 \mathrm{~min}$ (LFS pairing). Six single EPSCs were averaged and normalized to the averaged responses obtained 5 min before LTP induction. EPSC potentiation was assessed $30 \mathrm{~min}$ after induction.

Extracellular field experiments. P28 mice were killed with desflurane. Transverse slices (400 $\mu \mathrm{m})$ from the middle portion of each hippocampus were cut with a vibroslicer in the following ACSF (in mM): $124 \mathrm{NaCl}, 2 \mathrm{KCl}, 1.25$ $\mathrm{KH}_{2} \mathrm{PO}_{4}, 2 \mathrm{MgSO}_{4}, 2 \mathrm{CaCl}_{2}, 26 \mathrm{NaHCO}_{3}$, and 12 D-glucose; $4^{\circ} \mathrm{C}$, bubbled with $95 \% \mathrm{O}_{2} / 5 \%$ $\mathrm{CO}_{2}, \mathrm{pH}$ 7.4. Slices were placed in an interface chamber at $28-32^{\circ} \mathrm{C}$ and were perfused with ACSF, which in some experiments contained NVP-AAM077. Orthodromic synaptic stimulation was delivered alternately through two tungsten electrodes, one in the stratum radiatum and the other in the stratum oriens. Extracellular responses were monitored in the corresponding layers by two glass electrodes filled with ACSF. Assessment of synaptic efficacy and tetanization procedures were as described previously (Köhr et al., 2003).

All data were pooled across animals and are presented as mean \pm SEM. Statistical significance was evaluated using a two-tailed Student's $t$ test.

\section{A}
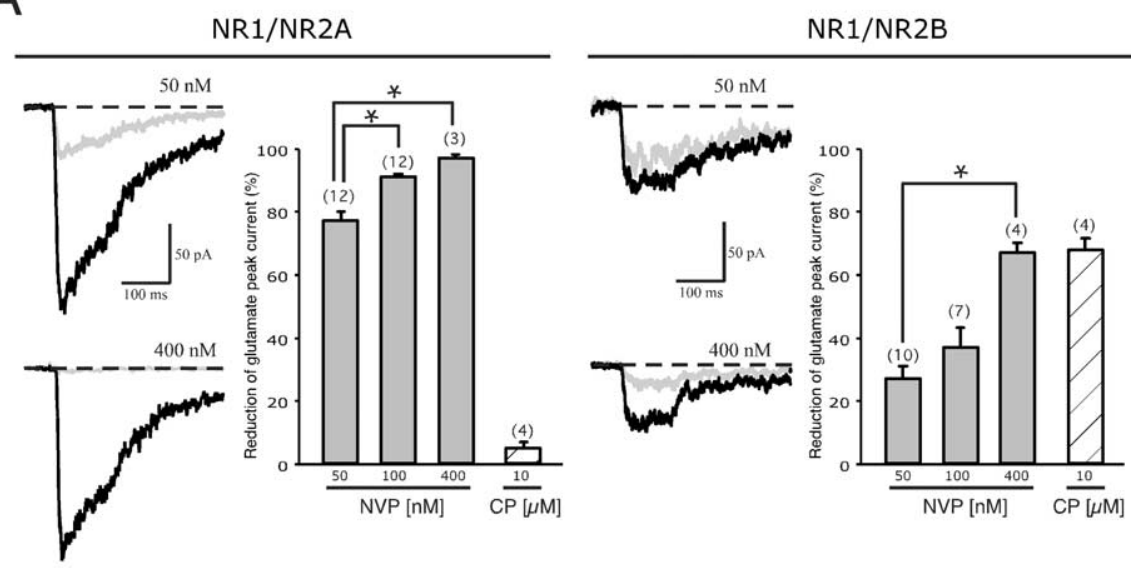

B
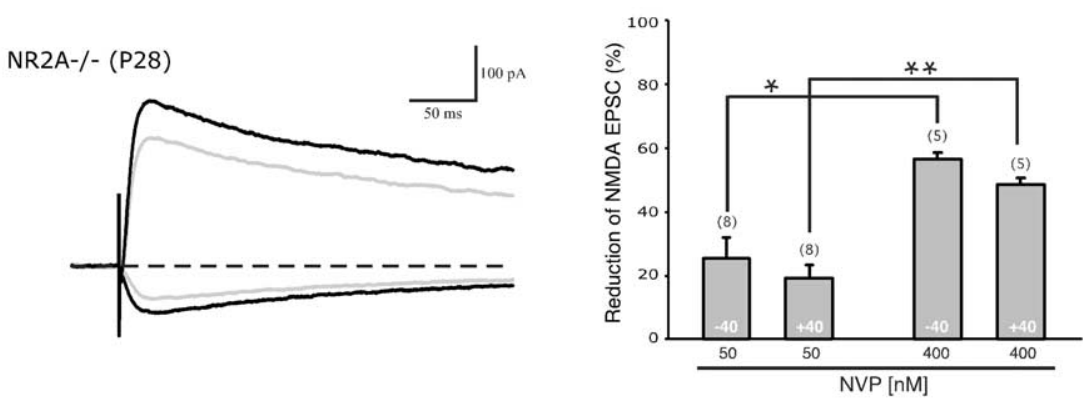

$\mathrm{NR} 2 \mathrm{~A}+/+(\mathrm{P} 28)$

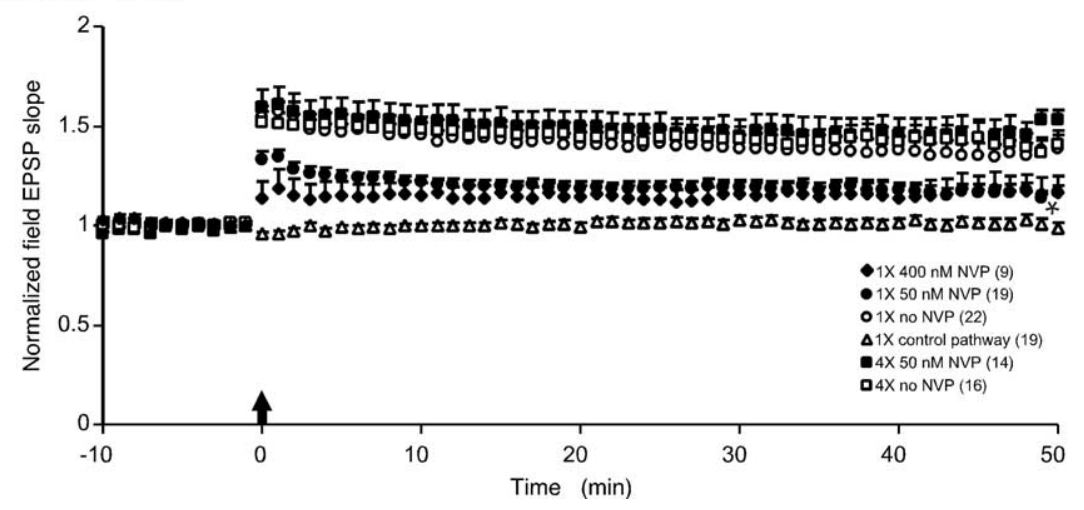

Figure 1. Effects of NVP-AAM077 on recombinant and synaptic NMDARs and on LTP elicited by tetanization. $A$, Example traces of glutamate-evoked currents in HEK293 cells expressing NR1/NR2A or NR1/NR2B receptors in the absence (black) and presence (gray) of NVP. Summary of results using different NVP concentrations (gray; ${ }^{*} p<0.0005$ ) or $10 \mu \mathrm{M}$ (P-101,606 (striped) is shown. $\boldsymbol{B}$, NMDA EPSC traces recorded in slices from P28 NR2A knock-out mice in $10 \mu \mathrm{m}$ bicuculline, $5 \mu \mathrm{m} \mathrm{NBQX}$, and $10 \mu \mathrm{m} \mathrm{glycine}$ at -40 and $+40 \mathrm{mV}$ in the absence (black) and presence (gray) of $50 \mathrm{~nm} \mathrm{NVP.} \mathrm{Summary} \mathrm{of} \mathrm{results} \mathrm{using} \mathrm{different} \mathrm{NVP} \mathrm{concen-}$ trations (gray; ${ }^{*} p=0.007$ and $\left.{ }^{* *} p=0.0004\right)$ is shown. C, Single tetanization ( $100 \mathrm{~Hz} ; 1$ s) induced LTP in hippocampal slices from P28 wild-type mice (open circles) in the presence of 50 and $400 \mathrm{~nm} \mathrm{NVP}\left({ }^{*} p<0.001\right.$ and ${ }^{*} p=0.003$, filled circles and diamonds, respectively). Repeated tetanizations ( 4 times with 5 min intervals) in the presence of $50 \mathrm{~nm} \mathrm{NVP} \mathrm{(filled} \mathrm{squares)} \mathrm{increased} \mathrm{LTP} \mathrm{to}$ levels obtained without the blocker (open squares). A representative control pathway is shown (open triangles). The arrow indicates the time of both the first and the fourth tetanization. Data are mean \pm SEM.

\section{Results}

Effects of the NR2A-specific antagonist NVP-AAM077 on recombinant and synaptic NR2B-type NMDARs

The NR2A-specific antagonist NVP-AAM077 (for details of the former name PEAQX, see Materials and Methods) has a 130-fold preference for recombinant human NR1/NR2A over NR1/NR2B receptors expressed in oocytes (Auberson et al., 2002), whereas subtype selectivity is only 13 -fold for recombinant rodent NMDARs (Feng et al., 2004). Indeed, NVP strongly reduced glutamate-evoked peak currents in HEK293 cells expressing ro- dent NR1/NR2A receptors but also reduced currents mediated by rodent NR1/NR2B receptors at all concentrations tested (Fig. 1A) $[50 \mathrm{nM}, 77 \pm 3 \%(n=12)$ vs $27 \pm 3 \%(n=10)$ and $77 \pm 3 \%$ $(n=12), p<0.0001 ; 100 \mathrm{nM}, 91 \pm 1 \%(n=12)$ vs $37 \pm 6 \%(n=$ $7), p<0.0005 ; 400 \mathrm{nM}, 97 \pm 1 \%(n=3)$ vs $67 \pm 3 \%(n=4), p<$ 0.005]. In contrast to NVP, the NR2B-specific antagonist CP, which is more potent than ifenprodil (Mott et al., 1998), is $>1000$-fold more selective for NR1/NR2B than NR1/NR2A receptors (Nagy et al., 2004). CP at $10 \mu \mathrm{M}$ reduced NR1/NR2B but not NR1/NR2A receptor currents (Fig. $1 A)(68 \pm 4 \%, n=4$ vs 
$5 \pm 2 \%, n=4 ; p=0.0002$ ). We next recorded pharmacologically isolated NMDA EPSCs from CA1 pyramidal cells in acute slices from 4-week-old NR2A ${ }^{-1-}$ mice (Sakimura et al., 1995). NR2Bmediated NMDA EPSCs were similarly reduced by NVP at -40 and $+40 \mathrm{mV}$, respectively (Fig. $1 B$ ) [50 nм NVP $(n=8), 25 \pm 6$ and $19 \pm 4 \%, p=0.25 ; 400 \mathrm{~nm} \mathrm{NVP}, 56 \pm 2 \%(n=5)$ and $46 \pm$ $3 \%, p<0.06]$, in agreement with results from recombinant NR1/ NR2B receptors.

Thus, NVP is not an NR2A-type selective antagonist but preferentially antagonizes NR2A-type NMDARs when used at $50 \mathrm{~nm}$.

\section{Tetanic stimulation}

A single tetanization in the hippocampal CA1 region $(100 \mathrm{~Hz}, 1 \mathrm{~s}$; wild type; P28) (see Materials and Methods) elicited robust LTP of the field EPSP (Fig. $1 C)(1.37 \pm 0.07 ; n=22)$. Consistent with the proposed role of NR2A-type NMDARs, $50 \mathrm{~nm} \mathrm{NVP}$ reduced but failed to block LTP $(1.17 \pm 0.04 ; n=19 ; p=0.017)$. Increasing the NVP concentration to $400 \mathrm{nM}$, which should completely prevent the activation of NR2A-type NMDARs based on the above results on recombinant NMDARs, did not further reduce LTP (Fig. 1C) $(1.15 \pm 0.07 ; n=9)$. Thus, LTP can be induced by tetanic stimulation in the presence of $400 \mathrm{~nm}$ NVP via NR2B-type NMDARs, which was not observed by Liu et al. (2004). Our results are consistent with studies demonstrating that NR2B-type NMDARs also induced LTP in mice with absent or impaired NR2A signaling, most efficiently after repeated tetanizations (Kiyama et al., 1998; Köhr et al., 2003). Indeed, we found additional proof for the role of NR2B in LTP induction in wild type when NR2A-type NMDARs were blocked by 50 nM NVP, because four tetanic stimulations increased LTP (Fig. 1C) $(1.46 \pm 0.08$; $n=14 ; p=0.001)$ to the level obtained without NVP $(1.43 \pm$ $0.07 ; n=16 ; p=0.88)$.

Thus, NR2B-type NMDARs induce LTP when NR2A-type signaling is genetically (Kiyama et al., 1998; Köhr et al., 2003) or pharmacologically impaired.

\section{Low-frequency stimulation}

In whole-cell experiments from CA1 neurons (P28), we paired low-frequency stimulation with postsynaptic depolarization (LFS pairing, $0.7 \mathrm{~Hz}, 3 \mathrm{~min} ; 0 \mathrm{mV}$ ) (see Materials and Methods). This protocol increased EPSCs (Fig. 2A) (2.05 $\pm 0.2 ; n=12)$, even in the presence of $50 \mathrm{~nm} \mathrm{NVP} \mathrm{(Fig.} 2 C)(2.12 \pm 0.2 ; n=10$; $p=0.8$ ), when NMDA EPSCs were reduced by $\sim 40 \%$ (Fig. $2 B$ ) $[-40 \mathrm{mV}, 39 \pm 4 \%(n=11) ;+40 \mathrm{mV}, 35 \pm 3 \%(n=11)]$. LTP was still induced in the presence of $100 \mathrm{nM} \mathrm{NVP}(1.8 \pm 0.5 ; n=3$; $p=0.9$ ) but was abolished at 200 and $400 \mathrm{~nm} \mathrm{NVP} \mathrm{(Fig.} \mathrm{2C)}$ $(1.2 \pm 0.3, n=3 ; 1.1 \pm 0.1, n=4)$. Thus, LTP could not be induced in the presence of $400 \mathrm{nM}$ NVP by LFS pairing, contrasting the results obtained by tetanic stimulation (see above). Note that the reduction of the NMDA EPSCs was doubled by $400 \mathrm{nM}$ NVP compared with $50 \mathrm{~nm}$ NVP (Fig. 2 B) $[-40 \mathrm{mV}, 81 \pm 1 \%$ $(n=7) ;+40 \mathrm{mV}, 65 \pm 3 \%(n=5)]$. Importantly, after preferred blockade of NR2A-type NMDARs (50 nM NVP), LTP is induced by NR2B-type NMDARs using LFS pairing. This contrasts with the observation of Liu et al. (2004), who used a comparable LFS pairing protocol ( $2 \mathrm{~Hz}, 1.7 \mathrm{~min} ;-5 \mathrm{mV})$ and $400 \mathrm{~nm} \mathrm{NVP}$, which in their hands reduced NMDA EPSCs by $53 \%$ and converted LTP into LTD.

To further substantiate that both NMDAR subtypes are capable of inducing LTP, we used $10 \mu \mathrm{M} \mathrm{CP}$, which like $50 \mathrm{~nm}$ NVP reduced NMDA EPSCs at $+40 \mathrm{mV}$ by $38 \pm 8 \%$ (Fig. $2 B)(n=11)$ (Steigerwald et al., 2000). LTP was not affected by CP (Fig. 2C) $(1.7 \pm 0.03 ; n=6 ; p=0.15)$, suggesting that LFS pairing induces
A

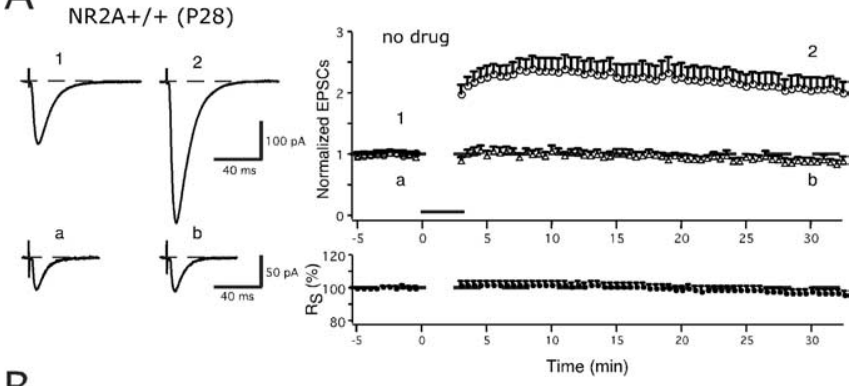

B $\mathrm{NR} 2 \mathrm{~A}+/+(\mathrm{P} 28)$

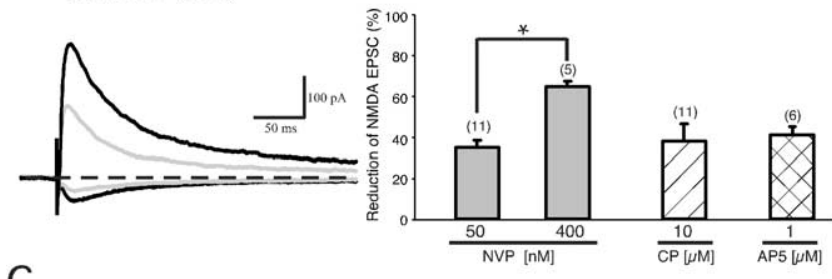

C

$\mathrm{NR} 2 \mathrm{~A}+/+(\mathrm{P} 28)$

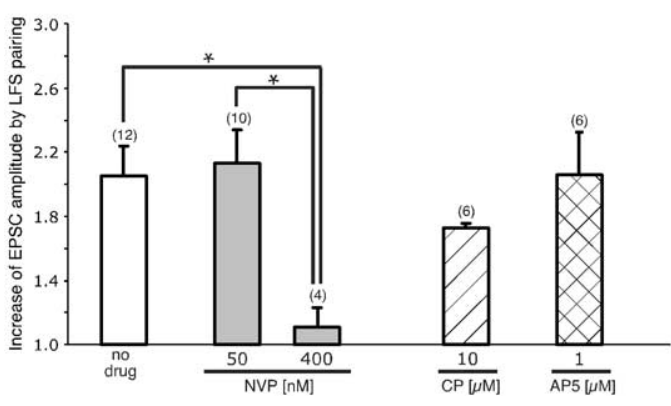

Figure 2. Comparison of the effects of different NMDAR antagonists on synaptic NMDA EPSCs and on LTP elicited by LFS pairing. $A$, EPSCS were evoked at $-70 \mathrm{mV}$ in $10 \mu \mathrm{MBMl}$ and 10 $\mu \mathrm{m}$ glycine in slices from P28 wild-type mice. LFS pairing (bar) increased EPSCs of the test (open circles) but not of the control pathway (open triangles). Representative EPSCs for test are labeled with 1 and 2 and, for control pathway, with a and $b . \boldsymbol{B}$, NMDA EPSC traces recorded in slices from P28 wild-type mice at -40 and $+40 \mathrm{mV}$ in the absence (black) and presence (gray) of 50 nм NVP. Summary of results at $+40 \mathrm{mV}$ using NVP (gray; ${ }^{*} p<0.0001$ ), CP (hatched), or D-AP-5 (cross-hatched) is shown. C, Changes in EPSC amplitude after LFS pairing in the absence (white) and presence $(\boldsymbol{B})$ of different NMDAR antagonists ( ${ }^{*} p=0.002$ ). Data are mean \pm SEM.

LTP regardless of which NR2 subtype is blocked. Similarly, even D-AP-5, a nonselective NMDAR antagonist, at a concentration reducing NMDA EPSCs by $\sim 40 \%$ (Fig. 2 B) $[-40 \mathrm{mV}, 43 \pm 4 \%$ $(n=6) ;+40 \mathrm{mV}, 41 \pm 4 \%(n=6)]$ (Nishiyama et al., 2000), failed to impair LTP (Fig. $2 C)(2.1 \pm 0.3 ; n=6 ; p=1.0)$.

Therefore, LFS pairing in the presence of NR2 subtypespecific antagonists fails to reveal a preferred NR2 subtype for LTP induction.

\section{Discussion}

Using a pharmacological approach, we demonstrate that LTP induction at CA3-to-CA1 synapses by different induction protocols does not require a particular NMDAR subtype. A 40\% blockade of synaptic NMDARs by three antagonists (two preferentially blocking NR2A- or NR2B-type NMDARs and one nonselectively blocking both subtypes) did not impair LFS pairing-triggered LTP. Furthermore, LTP induction by repeated tetanic stimulation was not prevented by the NR2A- and NR2B-preferring antagonists (Köhr et al., 2003; our observations).

Our findings that NR2B-type NMDARs can induce LTP are consistent with those obtained in genetically modified mice, in 
which NR2B expression was upregulated (Tang et al., 1999; Wong et al., 2002) or NR2A signaling was impaired (Kiyama et al., 1998; Köhr et al., 2003). This role for NR2B in LTP induction was not observed by Liu et al. (2004), who failed to induce LTP in the presence of $400 \mathrm{~nm}$ NVP by either tetanization or LFS pairing, although the NMDA EPSCs were only reduced by $53 \%$. In our study, NMDA EPSCs that were reduced to even higher extents by $400 \mathrm{nM}$ NVP still allowed LTP induction by tetanization in field recordings. In contrast, LTP could not be induced by LFS pairing in the presence of $400 \mathrm{~nm}$ NVP. Our contrasting results are not explained by the two recording configurations (field vs whole cell) but can be explained by the distinct induction protocols used. In a former study, which investigated LTP in CA1 neurons of genetically modified mice expressing NMDARs with reduced $\mathrm{Ca}^{2+}$ permeability (by $\sim 65 \%$ ) (Pawlak et al., 2005), we also observed that LTP was not induced by LFS pairing but by tetanic stimulation. Therefore, the frequency-dependent impairment of hippocampal LTP could be induced genetically and pharmacologically by NVP. This frequency-dependent impairment may be explained by NMDAR-mediated responses reaching threshold, probably because of summation during tetanization but not during LFS pairing (Pawlak et al., 2005).

A role for NR2B in LTP induction was not observed in the adult cortex (Massey et al., 2004). Different from hippocampal synapses (Steigerwald et al., 2000), CP did not reduce the NMDA EPSCs at cortical or cerebellar synapses in rodents older than P14 (Stocca and Vicini, 1998; Rossi et al., 2002), which may preclude NR2B-type NMDARs from inducing LTP in these but not in CA3-to-CA1 synapses. A partial restriction of the NR2B pathway at hippocampal synapses became evident during short tetanizations, which gave the NR2A-subtype advantage over NR2B, perhaps reflecting the faster signaling properties of NR2A than of NR2B (Erreger et al., 2005). Therefore, the relative contribution of the NR2 subtypes in LTP induction in CA1 neurons could be determined by the frequency pattern of synaptic stimulation, which might also influence the direction of the plasticity response. This is illustrated by a $40 \%$ NMDAR blockade, which did not reverse LTP induced by LFS pairing ( $0.7 \mathrm{~Hz}$ in our study) but reversed LTP after $20 \mathrm{~Hz}$ stimulation (Cummings et al., 1996) or spike timing (Nishiyama et al., 2000).

In summary, our results do not support the model that only NR2A-type NMDARs are responsible for LTP induction (Collingridge et al., 2004). Moreover, previous and unpublished observations (Hendricson et al., 2002) (W. Morishita and R. C. Malenka, personal communication) also cast doubt on the proposed preponderance of NR2B in LTD induction (Collingridge et al., 2004). Thus, rather than resulting from exclusive roles of NMDAR subtypes, the synaptic plasticity response appears to be directed by the pattern of synaptic activation, which recruits the major NMDAR subtypes to variable extents and triggers distinct signaling cascades.

\section{References}

Auberson YP, Allgeier H, Bischoff S, Lingenhoehl K, Moretti R, Schmutz M (2002) 5-Phosphonomethylquinoxalinediones as competitive NMDA receptor antagonists with a preference for the human $1 \mathrm{~A} / 2 \mathrm{~A}$, rather than 1A/2B receptor composition. Bioorg Med Chem Lett 12:1099-1102.

Chen C, Okayama H (1987) High-efficiency transformation of mammalian cells by plasmid DNA. Mol Cell Biol 7:2745-2752.

Collingridge GL, Isaac JTR, Wang YT (2004) Receptor trafficking and synaptic plasticity. Nat Rev Neurosci 5:952-962.
Cummings JA, Mulkey RM, Nicoll RA, Malenka RC (1996) $\mathrm{Ca}^{2+}$ signaling requirements for long-term depression in the hippocampus. Neuron $16: 825-833$.

Erreger K, Dravid SM, Banke TG, Wyllie DJ, Traynelis SF (2005) Subunitspecific gating controls rat NR1/NR2A and NR1/NR2B NMDA channel kinetics and synaptic signalling profiles. J Physiol (Lond) 563:345-358.

Feng B, Tse HW, Skifter DA, Morley R, Jane DE, Monaghan DT (2004) Structure-activity analysis of a novel NR2C/NR2D-preferring NMDA receptor antagonist: 1-(phenanthrene-2-carbonyl) piperazine-2,3-dicarboxylic acid. Br J Pharmacol 141:508-516.

Hendricson AW, Alek Miao CL, Lippmann MJ, Morrisett RA (2002) Ifenprodil and ethanol enhance NMDA receptor-dependent long-term depression. J Pharmacol Exp Ther 301:938-944.

Kiyama Y, Manabe T, Sakimura K, Kawakami F, Mori H, Mishina M (1998) Increased thresholds for long-term potentiation and contextual learning in mice lacking the NMDA-type glutamate receptor epsilon1 subunit. J Neurosci 18:6704-6712.

Köhr G, Jensen V, Koester HJ, Mihaljevic AL, Utvik JK, Kvello A, Ottersen OP, Seeburg PH, Sprengel R, Hvalby O (2003) Intracellular domains of NMDA receptor subtypes are determinants for long-term potentiation induction. J Neurosci 23:10791-10799.

Liu L, Wong TP, Pozza MF, Lingenhoehl K, Wang Y, Sheng M, Auberson YP, Wang YT (2004) Role of NMDA receptor subtypes in governing the direction of hippocampal synaptic plasticity. Science 304:1021-1024.

Massey PV, Johnson BE, Moult PR, Auberson YP, Brown MW, Molnar E, Collingridge GL, Bashir ZI (2004) Differential roles of NR2A and NR2B-containing NMDA receptors in cortical long-term potentiation and long-term depression. J Neurosci 24:7821-7828.

Mott DD, Doherty JJ, Zhang S, Washburn MS, Fendley MJ, Lyuboslavsky P, Traynelis SF, Dingledine R (1998) Phenylethanolamines inhibit NMDA receptors by enhancing proton inhibition. Nat Neurosci 1:659-667.

Nagy J, Horvath C, Farkas S, Kolok S, Szombathelyi Z (2004) NR2B subunit selective NMDA antagonists inhibit neurotoxic effect of alcoholwithdrawal in primary cultures of rat cortical neurones. Neurochem Int 44:17-23.

Nishiyama M, Hong K, Mikoshiba K, Poo MM, Kato K (2000) Calcium stores regulate the polarity and input specificity of synaptic modification. Nature 408:584-588.

Pawlak V, Jensen V, Schupp BJ, Kvello A, Hvalby Ø, Seeburg PH, Köhr G (2005) Frequency dependent impairment of hippocampal LTP from NMDA receptors with reduced calcium permeability. Eur J Neurosci, in press.

Rossi P, Sola E, Taglietti V, Borchardt T, Steigerwald F, Utvik JK, Ottersen OP, Köhr G, D’Angelo E (2002) NMDA receptor 2 (NR2) C-terminal control of NR open probability regulates synaptic transmission and plasticity at a cerebellar synapse. J Neurosci 22:9687-9697.

Sakimura K, Kutsuwada T, Ito I, Manabe T, Takayama C, Kushiya E, Yagi T, Aizawa S, Inoue Y, Sugiyama H, Mishina M (1995) Reduced hippocampal LTP and spatial learning in mice lacking NMDA receptor epsilon 1 subunit. Nature 373:151-155.

Sans N, Petralia RS, Wang YX, Blahos Jr J, Hell JW, Wenthold RJ (2000) A developmental change in NMDA receptor-associated proteins at hippocampal synapses. J Neurosci 20:1260-1271.

Steigerwald F, Schulz TW, Schenker LT, Kennedy MB, Seeburg PH, Köhr G (2000) C-terminal truncation of NR2A subunits impairs synaptic but not extrasynaptic localization of NMDA receptors. J Neurosci 20:4573-4581.

Stocca G, Vicini S (1998) Increased contribution of NR2A subunit to synaptic NMDA receptors in developing rat cortical neurons. J Physiol (Lond) 507:13-24.

Tang YP, Shimizu E, Dube GR, Rampon C, Kerchner GA, Zhuo M, Liu G, Tsien JZ (1999) Genetic enhancement of learning and memory in mice. Nature 401:63-69.

Wong RW, Setou M, Teng J, Takei Y, Hirokawa N (2002) Overexpression of motor protein KIF17 enhances spatial and working memory in transgenic mice. Proc Natl Acad Sci USA 99:14500-14505.

Yasuda H, Barth AL, Stellwagen D, Malenka RC (2003) A developmental switch in the signaling cascades for LTP induction. Nat Neurosci 6:15-16. 